\title{
Osteopenisi Olan Ankilozan Spondilitli Hastalarda Kemik Mineral Yoğunluğu ile Hastalık Aktivitesi Arasındaki ilişskinin Değerlendirilmesi
}

\author{
Assessment of the Relationship Between Bone Mineral Density and Disease Activity \\ in Ankylosing Spondylitis Patients with Osteopenia
}

Hayal Güler, Nilgün Üstün, Veli Enes Bolaç, Abdullah Erman Yağız, Ayhan Mansuroğlu, Erhan Yengil*, Ayşe Dicle Turhanoğlu

Mustafa Kemal Üniversitesi Tıp Fakültesi, Fiziksel Tıp ve Rehabilitasyon Anabilim Dalı, Hatay, Türkiye

*Mustafa Kemal Üniversitesi Tıp Fakültesi, Aile Hekimliği Anabilim Dalı, Hatay, Türkiye

\section{Özet}

Amaç: Ankilozan Spondilit (AS), kronik inflamatuvar bir hastalıktır. Lokal sitokin salınımı ve immobiliteye bağlı olarak AS'de spinal osteopeni yaygındır. Bu çalışmada, osteopenisi olan Ankilozan Spondilitli hastalarda kemik mineral yoğunluğu ile hastalık aktivitesi arasındaki ilişkiyi değerlendirdik.

Gereç ve Yöntem: Altmış bir AS'li hasta (26K, 35E) çalışmaya alındı. Hastaların; hastalık süresi, sabah tutukluğu süresi, schober testi, Eritrosit sedimentasyon hızı (ESH) ve C reaktif protein (CRP) değerleri kaydedildi. Hastalık aktivitesi Bath Ankylosing Spondylitis Disease Activity Index (BASDAI) ile değerlendirildi. Kemik mineral yoğunluğu (KMY) GE/LUNAR DPX PRO cihazı kullanılarak ölçüldü.

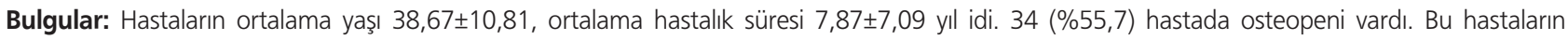

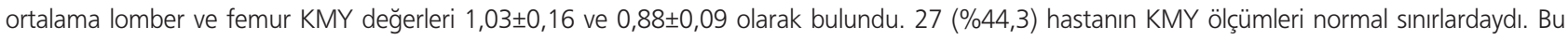

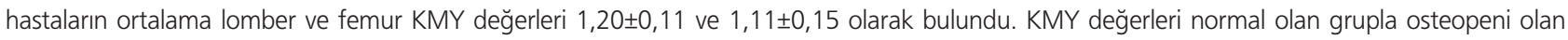
grup arasında ESH, CRP, ve BASDAI değerleri açısından istatistiksel olarak anlamlı fark bulunmadı $(p>0,05)$. Osteopenisi olan grupta, KMY değerleri ile ESH, CRP, ve BASDAI değerleri arasında bir korelasyon saptanmadı $(p>0,05)$.

Sonuç: Çalışmamızda, osteopenisi olan AS'li hastalarda kemik mineral yoğunluğu ile hastalık aktivitesi arasında ilişki bulunmamıştır. (Türk Osteoporoz Dergisi 2013;19: 28-31)

Anahtar kelimeler: Ankilozan spondilit, osteopeni, hastalık aktivitesi

\section{Summary}

Aim: Ankylosing Spondylitis (AS) is a chronic inflammatory disease. Spinal osteopenia is common in AS, probably due to immobility and local cytokine release. In this study, we evaluated the relationship between bone mineral density and disease activity in Ankylosing Spondylitis patients with osteopenia.

Material and Methods: Sixty one AS patients (26F, 35M) were enrolled in this study. The disease duration, morning stiffness, Schober tests, Erythrocyte Sedimentation Rate (ESR) and C Reactive Protein (CRP) were analyzed and recorded. Disease activity was evaluated by Bath Ankylosing Spondylitis Disease Activity Index (BASDAI). Bone mineral density (BMD) was measured by using GE/LUNAR DPX PRO equipment.

Results: The mean age and disease duration of the patients were 38.67 \pm 10.81 and $7.87 \pm 7.09$ year. There was osteopenia in 34 (\%55.7) patients. Spine and femur BMD values of this patients were 1.03 \pm 0.16 and $0.88 \pm 0.09$. BMD measurements of 27 (\%44.3) patient were found normally. Spine and femur BMD values of this patients were $1.20 \pm 0.11$ and $1.11 \pm 0.15$. There was not statistically significant difference between osteopenia and normal group in ESR, CRP, and BASDAI values ( $p>0.05)$. There was not correlation between BMD values and ESR, CRP, and BASDAI values in osteopenia group ( $p>0.05)$.

Conclusion: In our study, we did not find relationship between bone mineral density and disease activity in AS patients with osteopenia. (Turkish Journal of Osteoporosis 2013;19: 28-31)

Key words: Ankylosing Spondylitis, osteopenia, disease activity

Yazışma Adresi/Address for Correspondence: Dr. Hayal Güler, Mustafa Kemal Üniversitesi Tıp Fakültesi, Fiziksel Tıp ve Rehabilitasyon Anabilim Dalı, Hatay, Türkiye GSM: +90 5334675180 E-posta: hayalguler@yahoo.com Geliș Tarihi/Received: 13.05.2013 Kabul Tarihi/Accepted: 20.05.2013

Türk Osteoporoz Dergisi, Galenos Yayınevi tarafindan basılmıştır. / Turkish Journal of Osteoporosis, published by Galenos Publishing. 


\section{Giriş}

Ankilozan spondilit (AS) genel olarak sakroiliak eklemleri, vertebra ve intervertebral diski etkileyen, sidezmofit oluşumuna ve omurgada hareket kısıtııığına yol açan kronik inflamatuvar romatizmal bir hastalıktır $(1,2)$. AS'de ve diğer artritlerde yaygın olarak görülen, kemik mineral bozukluklarında etkili olan, inflamatuvar süreç, azalmış mobilite ve/veya değişen hormonal durum gibi çeşitli faktörlerin rolü hala tartışmalıdır (3). Osteopeni klinik olarak sadece hastalık şiddeti ağır olan hastalarda değil aynı zamanda hastalık şiddeti hafif mobilitesi az etkilenmiş olan hastlarda da görülmektedir. AS'li hastalarda azalmış kemik mineral yoğunluğu sonucunda osteoporoz gelişmesi yaygın olarak görülen komplikasyonlardan biridir. Prevalansı \%19-62 arasında değişmektedir. AS'li hastalarda düşük KMY ile hastalık aktivitesi arasındaki ilişkiyi değerlendiren çalışmalarda tartışmalı sonuçlar mevcuttur $(4,5)$. Bu sebeple çalışmamızda osteopenisi olan AS'li hastalarda KMY ile hastalık aktivitesi arasındaki ilişkiyi değerlendirmeyi planladık.

\section{Gereç ve Yöntem}

Çalışmaya New York kriterlerine göre AS tanısı almış 61 hasta dahil edildi (6). Hastaların yaş, hastalık süresi, sabah tutukluğu süresi ve mevcut tedavileri kaydedildi. Sigaraalkol kullanan hastalar çalışmaya alınmadı. Metabolik kemik hastalıkları (Paget hastalığı, osteomalazi, hiperparatiroidi), kronik tiroid, renal ve karaciğer hastalığı olanlar, glukokortikoid ve antikonvülzan gibi kemik kaybını artıran ilaç kullananlar, hormon replasman ve osteoporoz tedavisi alanlar çalışma dışı bırakıldı. Hastaların lomber mobilite değerlendirilmesinde modifiye Schober ölçümü kullanıldı. Bütün hastaların göğüs ekspansiyonları ölçüldü. Hastalık aktivitesi değerlendirilmesi için Bath Ankylosing Spondylitis Disease Activity Index (BASDAI) ölçümü kullanıldı (7). Vücut kitle indeksi (VKi) kg/boy m² olarak hesaplandı. Laboratuvar tetkiki olarak tüm hastaların eritrosit sedimentasyon hız (ESH mm/saat), C-reaktif protein(CRP mg/l), serum kalsiyum, fosfat, parathormon(PTH), ve alkalen fosfataz (ALP) seviyeleri ölçüldü. KMY ölçümleri, dual enerji x-ray absorbsiyometri (DEXA) kullanılarak lomber vertebra (L1-4) ve sol femur (femur boynu ve total) bölgelerinden yapıldı. DEXA ölçümleri GE/LUNAR DPX PRO cihazı ile gerçekleştirildi, sonuçlar standart T skoru kullanılarak kaydedildi. Hastaların kemik mineral yoğunlukları World Health Organisation (WHO) sınıflamasına göre tanımlandı (8). Hastalar osteopenisi olanlar ve KMY ölçümleri normal sınırlarda olanlar şeklinde 2 gruba ayrıldı. Osteoporozu olanlar çalışmaya alınmadı. Çalışmamız için etik kurul onayı alındı.

Veriler SPSS 13,0 paket programı kullanılarak değerlendirildi. Ki-kare ve Mann Whittney $U$ testi uygulandı. Osteopeni olan grupta KMY değerleri ile ESH, CRP, ve BASDAI skorları Pearson korelasyon katsayısı ile değerlendirildi. ( $p<0,05$ anlamlı olarak kabul edildi).

\section{Bulgular}

Tüm hastaların demografik özellikleri ve klinik bulguları Tablo 1'de verilmiştir. Hastaların $42(\% 68,85)$ 'si tedavi olarak günde 2 gr Sülfasalazin ve değişik dozlarda nonsteroid antienflamatuvar ilaç kullanıyor, 19'u $(\% 31,14)$ ise antiTNF tedavi alıyordu. Bütün hastalar düzenli olarak egzersiz yapıyorlardı. Hastalarımızın kortikosteroid kullanım öyküsü yoktu. $34(\% 55,7)$ hastada osteopeni vardı. Bu hastaların ortalama lomber ve femur KMY değerleri $1,03 \pm 0,16$ ve

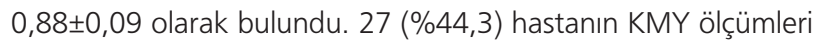
normal sınırlardaydı. Bu hastaların ortalama lomber ve femur

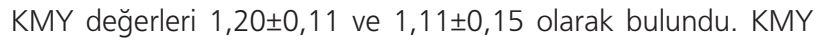
değerleri normal olan grupla osteopeni olan grup arasında ESH, CRP ve BASDAI değerleri açısından istatistiksel olarak anlamlı fark bulunmadı ( $p>0,05)$ (Tablo1). Osteopenik grubun, hastalık süresi ve sabah tutukluğu süresi normal gruptan daha uzundu. Fakat bu fark istatistiksel olarak anlamlı değildi (Tablo1).

\section{Tablo1. Hastaların demografik özellikleri ve klinik bulguları}

\begin{tabular}{|l|c|c|c|}
\hline & $\begin{array}{c}\text { Osteopenik grup } \\
\mathbf{n = 3 4} \\
\text { ortalama } \pm \text { SD }\end{array}$ & $\begin{array}{c}\text { Normal grup } \\
\mathbf{n = 2 7} \\
\text { ortalama } \pm \text { SD }\end{array}$ & p değeri \\
\hline Yaş & $41,44 \pm 11,01$ & $38,18 \pm 9,65$ & 0,1622 \\
\hline Cinsiyet(K/E) & $15 / 19$ & $11 / 16$ & 0,791 \\
\hline VKI(kg/m²) & $26,35 \pm 4,46$ & $26,13 \pm 5,28$ & 0,882 \\
\hline Hastalık süresi(yll) & $9,23 \pm 8,17$ & $6,16 \pm 5,09$ & 0,151 \\
\hline Sabah tutukluğu süresi (dk) & $31,75 \pm 45,11$ & $26,25 \pm 30,09$ & 0,052 \\
\hline BASDAl & $2,86 \pm 1,96$ & $2,87 \pm 1,61$ & 0,816 \\
\hline ESH(mm/saat) & $28,47 \pm 22,87$ & $22,66 \pm 16,97$ & 0,285 \\
\hline CRP(mg/L) & $8,23 \pm 7,05$ & $7,17 \pm 6,38$ & 0,391 \\
\hline $\begin{array}{l}\text { ESH(mm/saat): Eritrosit Sedimentasyon Hizı } \\
\text { CRP(mg/L): C-Reaktif Protein } \\
\text { BASDAl: Bath Ankylosing Spondylitis Disease Activity Index }\end{array}$ & & \\
\hline
\end{tabular}


Osteopenisi olan grupta, KMY değerleri ile ESH, CRP ve BASDAI değerleri arasında bir korelasyon saptanmadı $(p>0,05)$.

\section{Tartışma}

Ankilozan spondilit etyolojisi bilinmeyen, spinal eklemlerde ve komşu yapılarda belirgin inflamasyon ile karekterize, omurgada progresif kemik füzyonuna yol açan kronik inflamatuvar bir hastalıktır. AS'li hastalardaki önemli ve sık bir komplikasyon da osteoporozdur. AS'de görülen osteoporoz nedenleri arasında immobilite, kortikosteroid kullanımı, inflamatuvar sitokinlere bağlı olarak gelişen kemik metabolizmasındaki bozukluklar, seks steroidlerindeki eksiklik ve eşlik eden sessiz bağırsak hastalığı sayılabilir (9).

Çalışmamızda, osteopenisi olan AS'li hastalarda kemik mineral yoğunluğu ile hastalık aktivitesi arasında ilişki bulunmamıştır. AS'de kemik kaybı hem omurgada hem de femur boyun bölgesinde hastalığın erken döneminden başlayarak ileri dönemlerinde de devam eder (10). Özellikle ilaçlara rağmen inflamasyonun engellenemediği ve hastalık süresinin uzun olduğu durumlarda kemik kaybı fazladır $(11,12)$. Osteoporoz ve osteopeni prevalansı kadın ve erkeklerde eşittir. Erkeklerde sindesmofitlerin yüksek prevalansta olması lomber bölgede hatalı olarak artmış KMY'na yol açabilir $(4,5)$. Bir çalışmada, düşük KMY ile ileri yaş, hastalık süresi, sindesmofit varlığı, azalmış bel mobilitesi, glukokortikoid kullanımı ve inflamasyonunun laboratuar belirleyicileri arasında ilişki olduğu fakat düşük KMY ile BASDAI, BASFI, BAS-G veya ASDAS skorları arasında ilişki olmadığı gösterilmiştir (13). AS'de inflamasyon ve yeni kemik oluşumu arasındaki etkileşim açık değildir. Osteokalsinin inflamatuvar belirleyicilerin düzeyinden ilişkisiz olarak azalmış, normal veya artmış olabileceği gösterilmiştir. MR'a dayalı çalışmalarda çoğunlukla sindesmofitlerin inflamasyonla ilişkisi olmadığı öne sürülmüştür. AS'de inflamasyon baskılandığı dönemde de yeni kemik oluşumu varlığı gösterilmiştir. Böylece, bu çalışmada $A S^{\prime}$ de kemik kaybı ve yeni kemik oluşumunun direkt inflamasyonla bağlantılı olmadığı bu hipotez için daha ileri çalışmaların gerekli olduğu öngörülmüştür (14). Epidemiyolojik çalışmalar proinflamatuar sitokinlerin azalmış kemik kitlesiyle ilişkili olduğunu göstersede bu yöndeki kanıtlar hala sınırlıdır. Inflamasyon osteoklastik aktiviteyi etkileyerek kemik kaybına yol açan TNF-alfa, IL-1ve IL-6 gibi proinflamatuar sitokinlerin etkisine bağlı olarak kemik metabolizmasını etkileyebilir (15). Karapolat ve arkadaşları, KMY ölçümleri ile BASMI skorları arasında anlamlı bir negatif korelasyon bulurken, BASDAI ve BASFI skorları arasında bir ilişki saptamamışlardır (16). Çakmak ve arkadaşları ise KMY ölçümleri ile gerek hastalık süresi gerekse hastalık aktivite kriterlerinden olan BASFI ve BASDAI arasında bir ilişki saptamamışlardır (17). Aynı şekilde, Paker ve arkadaşları da AS'li hastalarda KMY değerleri ile BASFI, BASDAI, BASMI ve BASGI skorları arasında ilişki saptamamışlardır (9). Bu bulgular bizim çalışmamızı desteklemektedir ve AS'li hastalarda osteoporoz etyopatogenezinde hastalık aktivitesi dışında, fiziksel aktivitede azalma, yetersiz beslenme durumu,
D vitamini eksikliği, kalsiyum alımında azalma gibi faktörlerin de rol oynadığını göstermektedir. Bununla birlikte, bazı çalışmalarda inflamasyonun omurgada kemik kaybına yol açtığı öne sürülmüştür. Anti TNF tedavi alan hastalarda sadece semptomlarda azalma olmayıp, KMY'nda artış olması da indirekt olarak bu çalışmaları desteklemektedir $(18,19)$. Buna benzer olarak, yapılan diğer çalışmalarda hastalık aktivitesi parametreleri (ESR, CRP düzeyleri ve BASDAI) ile KMY değerleri arasında ilişki olduğu, inflamatuar mediatörlerin AS'li hastaların kemik kaybında önemli bir rol oynadığı gösterilmiştir $(20,21,22)$. Görüldüğü gibi, bu konuda yapılmış çalışmaların sonuçları tartışmalıdır.

Sonuç olarak; bizim çalışmamızda, osteopenisi olan AS'li hastalarda kemik mineral yoğunluğu ile hastalık aktivitesi laboratuvar belirleyicilerinden olan ESH, CRP ve BASDAI skorları arasında ilişki bulunmamıştır.

\section{Kaynaklar}

1. Donnelly S, Doyle DV, Denton A, Rolfe I, McCloskey EV, Spector TD. Bone mineral density and vertebral compression fracture rates in ankylosing spondylitis. Ann Rheum Dis 1994;53:117-21.

2. Mitra D, Elvins DM, Speden DJ, Collins AJ. The prevalence of vertebral fractures in mild ankylosing spondylitis and their relationship to bone mineral density. Rheumatology (Oxford) 2000;39:85-9.

3. Baek HJ, Kang SW, Lee YJ, Shin KC, Lee EB, Yoo CD, et al. Osteopenia in men with mild and severe ankylosing spondylitis. Rheumatol Int 2005:26:30-4.

4. Karberg K, Zochling J, Sieper J, Felsenberg D, Braun J. Bone loss is detected more frequently in patients with ankylosing spondylitis with syndesmophytes. J Rheumatol 2005;32:1290-8.

5. Mullaji AB, Upadhyay SS, Ho EK. Bone mineral density in ankylosing spondylitis. DEXA comparison of control subjects with mild and advanced cases. J Bone Joint Surg Br 1994;76:660-5.

6. Moll JM, Wright V. New York clinical criteria for ankylosing spondylitis: a statistical evaluation. Ann Rheum Dis 1973;32:35463.

7. Garrett S, Jenkinson T, Kennedy LG Whitelock H, Gaisford P, Calin A. A new approach to defining disease status in ankylosing spondylitis: The Bath Ankylosing Spondylitis Disease Activity Index. J Rheumatol 1994;21:2286-91.

8. Kanis JA, Melton LJ 3rd, Christiansen C, Johnston CC, Khaltaev N. The diagnosis of osteoporosis. J Bone Min Res 1994;9:1137-41.

9. Paker N, Tekdöş D, Erbil M, Soy D, Bardak A. Ankilozan Spondilitte Kemik Kaybı: Kontrollü Çalışma Osteoporoz Dünyasından 2006;12:81-3.

10. Lange U, Kluge A, Strunk J, Teichmann J, Bachmann G. Ankylosing spondylitis and bone mineral density-what is the ideal tool for measurement. Rheumatol Int 2005;26:115-20.

11. El Maghraoui A. Osteoporosis and ankylosing spondylitis. Joint Bone Spine 2004;71:291-5.

12. Gratacos J, Collado A, Pons F, Osaba M, Sanmarti R, Roque $M$, et al. Significant loss of bone mass in patients with early, active ankylosing spondylitis. A follow up study. Arthritis Rheum 1999:42:2319-24

13. Klingberg E, Lorentzon M, Mellström D, Geijer M, Göthlin J, Hilme $E$, et al. Osteoporosis in ankylosing spondylitis - prevalence, risk factors and methods of assessment Arthritis Res Ther 2012;14:108-20.

14. Korkosz M, Gąsowski J, Grzanka P, Gorczowski J, Pluskiewicz W, Jeka $S$. Baseline new bone formation does not predict bone loss in ankylosing spondylitis as assessed by quantitative computed tomography (QCT) - 10-year follow-up BMC Musculoskelet Disord 2011:12:121-8

15. MacDonald BR, Gowen M. Cytokines and bone. Br J Rheumatol 1992;31:149-55. 
16. Karapolat H, Eyigör S, Akkoç Y, Kirazı Y, Sarı I, Akar S ve ark. Aksiyal iskelet Tutulumu Olan Erkek Ankilozan Spondilit Hastalarında Bath indekslerinin Osteoporoz ile ilişkisi. Romatizma 2008;23:82-6.

17. Çakmak B, Sarı H. Ankilozan Spondilit'te Kemik Mineral Yoğunluğu. Osteoporoz Dünyasından 2003;94:141-5

18. Briot K, Gossec L, Kolta S, Dougados M, Roux C. Prospective assessment of body weight, body composition, and bone density changes in patients with spondyloarthropathy receiving anti-tumour necrosis factor-alpha treatment. J Rheumatol 2008;35:855-61.

19. Allali F, Breban M, Porcher R, Maillefert JF, Dougados M, Roux C. Increase in bone mineral density of patients with spondyloarthropathy treated with anti-tumour necrosis factor alpha. Ann Rheum Dis 2003;62:347-9.
20. Grazio S, Kusic Z, Cvijetic, S, Grubisic F, Balenovic A, Nemcic T et al. Relationship of bone mineral density with disease activity and functional ability in patients with ankylosing spondylitis: a crosssectional study Rheumatol Int 2012;32:2801-8.

21. Mermerci Başkan B, Pekin Doğan Y, Sivas F, Bodur H, Özoran $K$. The relation between osteoporosis and vitamin $D$ levels and disease activity in ankylosing spondylitis. Rheumatol Int 2010;30:375-81.

22. Ghozlani I, Ghazi M, Nouijai A Mounach A, Rezqi A, Achemlal $L$, et al. Prevalence and risk factors of osteoporosis and vertebral fractures in patients with ankylosing spondylitis. Bone 2009;44:772-6. 